\title{
Cellulase production and efficient saccharification of biomass by a new mutant Trichoderma afroharzianum MEA-12
}

\author{
Zhi-Qing Peng ${ }^{1}$, Chuang Li ${ }^{1}$, Yi Lin' ${ }^{1}$, Sheng-Shan Wu ${ }^{1,2,3}$, Li-Hui Gan 1,2,3, Jian Liu 1,2,3, Shu-Liang Yang ${ }^{1,2,3}$, \\ Xian-Hai Zeng ${ }^{1,2,3^{*}}$ (D) and Lu Lin ${ }^{1,2,3}$
}

\begin{abstract}
Background: Cellulase plays a key role in converting cellulosic biomass into fermentable sugar to produce chemicals and fuels, which is generally produced by filamentous fungi. However, most of the filamentous fungi obtained by natural breeding have low secretory capacity in cellulase production, which are far from meeting the requirements of industrial production. Random mutagenesis combined with adaptive laboratory evolution (ALE) strategy is an effective method to increase the production of fungal enzymes.

Results: This study obtained a mutant of Trichoderma afroharzianum by exposures to N-methyl-N'-nitro-N-nitrosoguanidine (MNNG), Ethyl Methanesulfonate (EMS), Atmospheric and Room Temperature Plasma (ARTP) and ALE with high sugar stress. The T. afroharzianum mutant MEA-12 produced 0.60, 5.47, 0.31 and $2.17 \mathrm{IU} / \mathrm{mL}$ FPase, CMCase, pNPCase and pNPGase, respectively. These levels were 4.33, 6.37, 4.92 and 4.15 times higher than those of the parental strain, respectively. Also, it was found that T. afroharzianum had the same carbon catabolite repression (CCR) effect as other Trichoderma in liquid submerged fermentation. In contrast, the mutant MEA-12 can tolerate the inhibition of glucose (up to $20 \mathrm{mM}$ ) without affecting enzyme production under inducing conditions. Interestingly, crude enzyme from MEA-12 showed high enzymatic hydrolysis efficiency against three different biomasses (cornstalk, bamboo and reed), when combined with cellulase from $T$. reesei Rut-C30. In addition, the factors that improved cellulase production by MEA-12 were clarified.
\end{abstract}

Conclusions: Overall, compound mutagenesis combined with ALE effectively increased the production of fungal cellulase. A super-producing mutant MEA-12 was obtained, and its cellulase could hydrolyze common biomasses efficiently, in combination with enzymes derived from model strain T. reesei, which provides a new choice for processing of bioresources in the future.

Keywords: Trichoderma afroharzianum, Compound mutagenesis, Adaptive laboratory evolution, Cellulase, Biomass

\section{Background}

In biorefinery process, cellulase plays a key role in converting cellulosic biomass into fermentable sugar to produce chemicals and biofuels [1]. Many microorganisms are known to produce cellulase including bacteria, fungi

\footnotetext{
*Correspondence: xianhai.zeng@xmu.edu.cn

${ }^{1}$ College of Energy, Xiamen University, Xiamen 361102, China

Full list of author information is available at the end of the article
}

and actinomycetes [2-4]. Among microbial sources, filamentous fungi have higher secretory capacity and considered to be the most promising cellulase producers [3]. However, most of the filamentous fungi obtained by natural breeding have incomplete enzyme systems, which are far from meeting the requirements of industrial production [5], so the selection of strains with high yield and quality of cellulase is essential to expand the application range of them. original author(s) and the source, provide a link to the Creative Commons licence, and indicate if changes were made. The images or other third party material in this article are included in the article's Creative Commons licence, unless indicated otherwise in a credit line to the material. If material is not included in the article's Creative Commons licence and your intended use is not permitted by statutory regulation or exceeds the permitted use, you will need to obtain permission directly from the copyright holder. To view a copy of this licence, visit http://creativecommons.org/licenses/by/4.0/. The Creative Commons Public Domain Dedication waiver (http://creativeco mmons.org/publicdomain/zero/1.0/) applies to the data made available in this article, unless otherwise stated in a credit line to the data. 
Classic physical or chemical mutagenesis is a kind of strategy that can effectively improve the performance of strains, especially for increasing enzyme yields $[6,7]$. The usual reported mutagenesis techniques are UV radiation, Heavy ion, Atmospheric and Room Temperature Plasma (ARTP), N-methyl-N'-nitro-N-nitrosoguanidine (MNNG) and Ethyl Methanesulfonate (EMS) [8-12]. Chemical mutagenesis can cause mutations in microorganisms by adding chemical mutagens, which is highly specific to DNA [13]. ARTP is a recently developed whole-cell mutagenesis tool based on radio frequency atmospheric pressure glow discharge plasma. The active particles produced by ARTP act on microorganisms to change the permeability of cell membranes, then, active particles and oxidative free radicals enter the cells and interact with biological macromolecules such as DNA and proteins to cause direct and/or indirect damage to DNA [14]. The use of single mutagenesis or simple compound mutagenesis treatment has been reported [11, 12], whereas MNNG/EMS/ARTP has not.

Adaptive laboratory evolution (ALE) also can achieve the phenotypic optimization. ALE refers to the realization of microbial evolution by imposing human interference and controlling the growth environment of microbes [15]. Compared with metabolic engineering, ALE does not need to consider the intricate and intersecting metabolic network of microorganisms [16]. It only needs to design the corresponding interference factors according to the target. In this case, most of the cellulase-producing Trichoderma spp. have catabolite repression [17]. High concentration of metabolic repressors produced during the fermentation process greatly hinders the production of cellulase [17]. Therefore, it is possible to combine mutagenesis with ALE and artificially adjust the screening medium components and the concentration of metabolic repressors contained at different mutagenesis stages to improve the enzyme production.

In this study, MNNG/EMS/ARTP mutagenesis combined with ALE method was used to improve cellulase production in $T$. afroharzianum. Subsequently, it was found that the mutant can tolerate the inhibition of glucose (up to $20 \mathrm{mM}$ ) without affecting enzyme production under inducing conditions. Interestingly, crude enzyme from the mutant showed high enzymatic hydrolysis efficiency against three common biomasses (cornstalk, bamboo and reed), which were pretreated by cooking with active oxygen and solid alkali (CAOSA), when combined with cellulase from $T$. reesei Rut-C30. In addition, real-time reverse transcription quantitative PCR (RT-qPCR) was employed to analyze the transcription levels of major cellulase genes and transcription factors genes in isolated mutant.

\section{Results and discussion \\ Development of a compound mutagenesis combined with ALE method}

To optimize the screening efficiency of high-yield cellulase mutants, a strategy of compound mutagenesis combined with microbial adaptive laboratory evolution (ALE) was established (Fig. 1a). By artificially adjusting the components of screening medium (SM 1-3) and the concentration of environmental factors (such as metabolic repressors) in different mutagenesis stages, the ability of filamentous fungi to produce enzymes is improved. Compared with previous mutagenesis methods, the new strategy provides not only different mutagenesis sources, but also a screening medium corresponding to each round of mutagenesis, which has strong purpose and high practicability. As the mutagenesis round progressed, the proportion of mutants with high cellulase activity in the total mutants increased (Table 1). Specifically, in the first round of mutagenesis, a modified classic cellulosecongo red medium was used for preliminary screening [18]. Both the wild-type and the mutant M-84 colonies showed clear zones around colonies, and the clear zones around the mutant M-84 colonies became slightly larger (Fig. 1b). In the second round of mutagenesis, the modified esculin medium was used for preliminary screening [19]. The glycosidic bond of esculin was destroyed by $\beta$-glucosidase and complexed with ferric citrate to form a brown-black substance [19]. The brown-black substance formed by ME-10 colonies was darker and larger

Table 1 Number and positive mutation rate of wild strain T. afroharzianum obtained by three rounds of mutagenesis

\begin{tabular}{|c|c|c|c|c|c|c|c|}
\hline \multirow[t]{2}{*}{ Mutagenic round } & \multirow[t]{2}{*}{ Mutagenic method } & \multirow{2}{*}{$\begin{array}{l}\text { Total number of } \\
\text { mutants }\end{array}$} & \multicolumn{4}{|c|}{ Number of strains screened by enzyme activity } & \multirow{2}{*}{$\begin{array}{l}\text { Positive } \\
\text { mutation } \\
\text { rate (\%) }\end{array}$} \\
\hline & & & - & + & ++ & +++ & \\
\hline Round 1 & MNNG & 84 & 60 & 19 & 4 & 1 & 28.57 \\
\hline Round 2 & EMS & 102 & 75 & 17 & 6 & 4 & 26.47 \\
\hline Round 3 & ARTP & 86 & 61 & 11 & 8 & 6 & 29.07 \\
\hline
\end{tabular}

"-" refers to the negative mutants; $+"$ " refers to the mutants with low activity;" $++"$ refers to the mutants with middle activity; $+++"$ refers to the mutants with high activity 

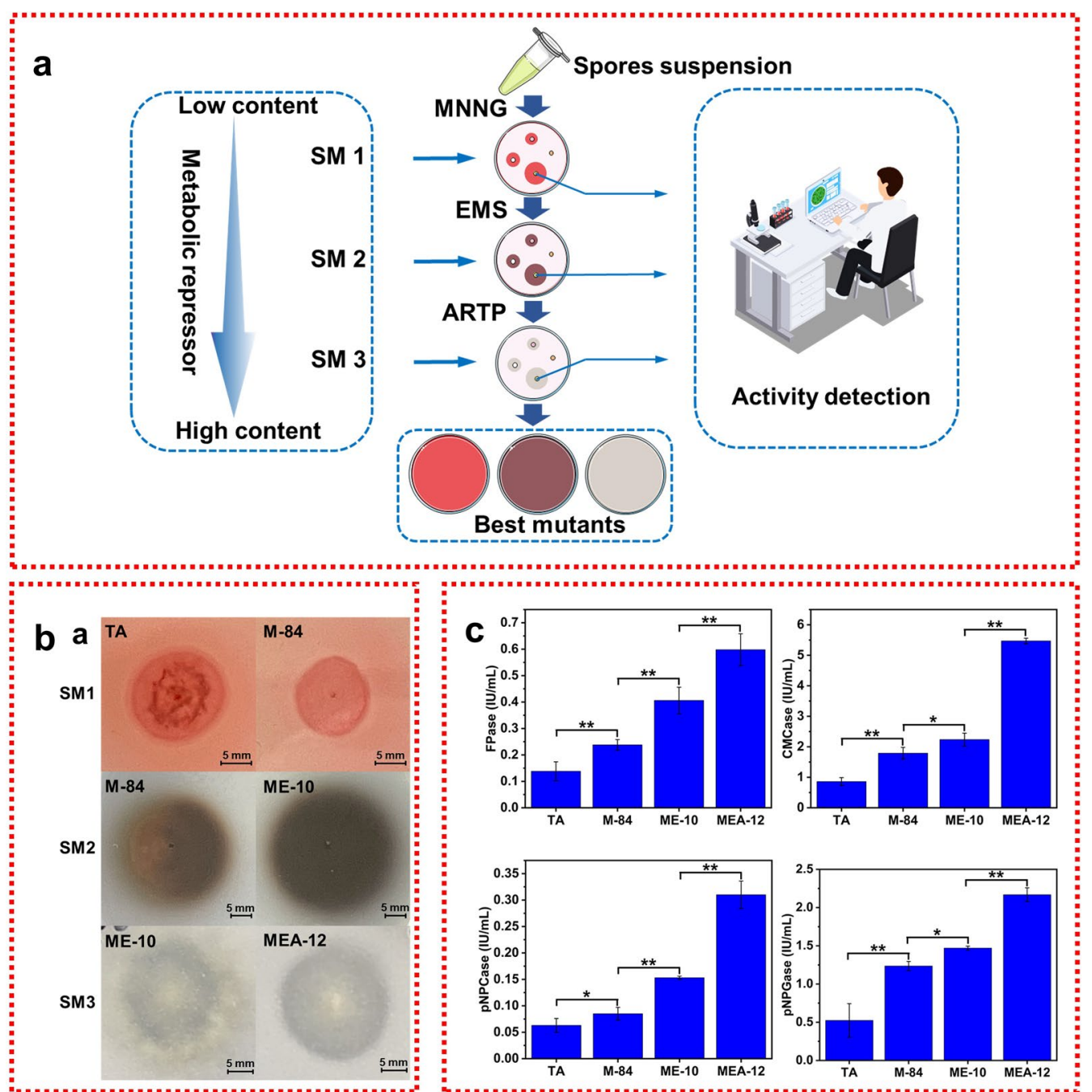

Fig. 1 Scheme of mutation procedure (a), phenotypic investigation of T. afroharzianum and its mutants, grown on selection medium $\mathbf{b}$ and their cellulase activities in fermentation medium (c). TA is a wild type of T. afroharzianum; M-84 is the best mutant in first round of mutagenesis; ME-10 is the best mutant in second round of mutagenesis; MEA-12 is the best mutant in third round of mutagenesis. Error bars indicate the mean \pm SD of three biological replicates and statistical significance was calculated by Student's $t$ test ${ }^{*}(p<0.05)$ and $\left.{ }^{* *}(p<0.01)\right)$

than that of mutant M-84 (Fig. 1b). In the third round of mutagenesis, the modified MCC medium was used for preliminary screening. The clear zones around colonies of mutant MEA-12 were larger than that of ME-10 (Fig. 1b). Inoculated in the fermentation medium, the cellulase activity of the above apparent positive mutant strains was significantly improved (Fig. 1c). These data confirmed that the compound mutagenesis combined with microbial ALE strategy was an effective method for screening high-producing cellulase strains.

\section{Mutagenesis and screening}

The mutagenesis was performed in three rounds: (1) one round of MNNG, (2) one round of EMS, and (3) one round of ARTP. Before each round of mutagenesis, a preliminary experiment on the relationship between lethality and positive mutation rate was done. In each round of mutagenesis, with the increased of time, the lethality rate of the strain increased, while the positive mutation rate reached a peak. In the first round of MNNG mutagenesis, when the mutagenesis time was $50 \mathrm{~min}$, the lethality rate of the strain exceeded $99 \%$ (Fig. 2a). The lethality rate was resulted in $100 \%$ when the mutagenesis time reached 90 min (Fig. 2a). Combining with the positive mutation rate curve, it indicated that the optimal treatment time for the first round of mutagenesis was $50 \mathrm{~min}$. Similarly, the optimal treatment time for the second round of EMS mutagenesis was $70 \mathrm{~min}$ and the optimal treatment 

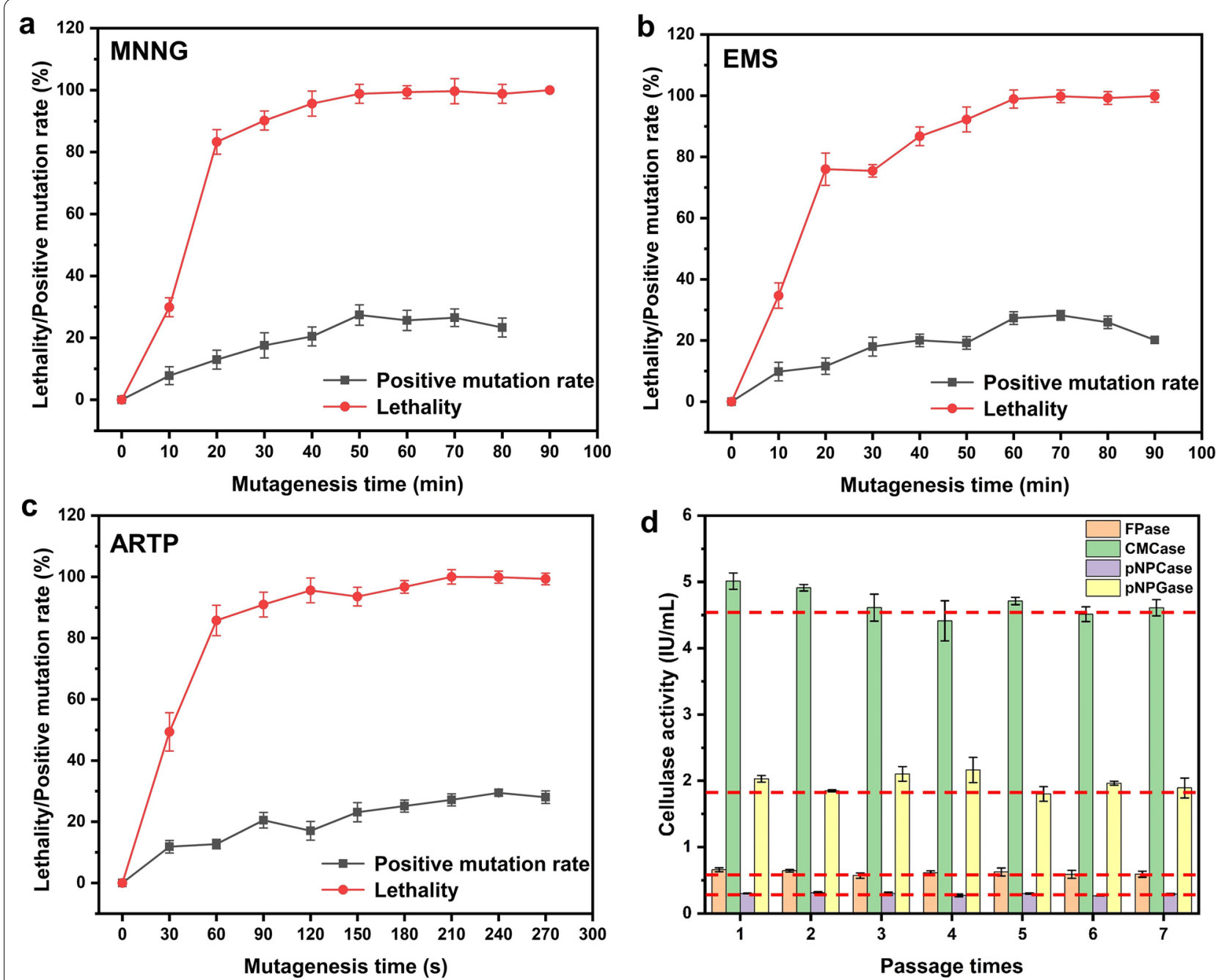

Fig. 2 Lethality and positive mutation rate of T. afroharzianum in each round of mutagenesis $\mathbf{a}-\mathbf{c}$ and subculture stability of high-yielding mutant MEA-12 under the inducing condition (d). Error bars indicate the mean \pm SD of three biological replicates

time for the third round of ARTP mutagenesis was $240 \mathrm{~s}$ (Fig. 2b, c).

In the first round of MNNG mutagenesis, a total of 84 mutants were obtained (Table 1). Combined with the SM1 for preliminary screening, there were 24 colonies with a higher diameter ratio between each colony and its clear zone than those of the wild type. Among them, 12 mutants' cellulase activity in the re-screening were higher than the wild type. The mutant with the highest enzyme activity was numbered 84, named M-84 (Additional file 1: Fig. S1). After the second round of EMS mutagenesis, a total of 102 mutants were obtained (Table 1). Combined with the SM2 for preliminary screening, there were 27 colonies with darker color and larger diameter than those of the M-84. Among them, 4 mutants' cellulase activity in the re-screening were higher than those of the M-84. The mutant with the highest enzyme activity was numbered
10, named ME-10 (Additional file 1: Fig. S2). After the third round of ARTP mutagenesis, the total number of mutants obtained was 86 (Table 1). Combined with the SM3 for preliminary screening, there were 25 colonies with a higher diameter ratio between each colony and its clear zone than those of the ME-10. Among them, the cellulase activities of 18 mutants in the re-screening were higher than those of the ME-10. The mutant with the highest enzyme activity was numbered 12, named MEA12 (Additional file 1: Fig. S3).

After multiple rounds of mutagenesis, the cellulase of MEA-12 was significantly improved compared with the wild type (FPase increased 4.33-fold, CMCase increased 6.37-fold, pNPCase increased 4.92-fold, pNPGase increased 4.15 -fold). This appears to be attributable to the compound mutagenesis combined with microbial ALE strategy, which avoided the defect that the repeated 
processing of a single mutagenesis technique leading to reducing the efficiency of mutagenesis [20]. The selected substrates (CMC-Na, esculin, MCC) at each stage can improve the cellulase activity of the target strain.

To evaluate the genetic stability of the mutant MEA-12, the cellulase activity was measured in the fermentation medium after seven consecutive subcultures. No significant change in cellulase activities was observed after the subcultures (Fig. 2d).

\section{Cellulase activity analysis of the mutant MEA-12}

Cellulose degradation is attributed to the synergistic action of three complementary enzyme activities: (1) endoglucanases (EGs); (2) cellobiohydrolases (CBHs); (3) $\beta$-glucosidases (BGs) [21]. In this study, a cellulase high-producer MEA-12 was obtained by compound mutagenesis combined with microbial ALE method. To further compare the difference in the enzyme production between parental strain and mutant strain, the fermentation time for optimal cellulase production was measured. The results showed that the enzyme activity of the parental strain $T$. afroharzianum (TA) reached the maximum on the day 6 , while that of the mutant MEA-12 was on the day 4 (Fig. 3). This will greatly shorten the fermentation cycle of enzyme production and reduce production costs.

Moreover, the specific activities (IU/mg) of strain MEA-12 which were calculated based on protein mass increased 1.44, 1.51, 1.29 and 1.05 times in FPase, CMCase, pNPCase and pNPGase, respectively, compared with that of the parental strain (Fig. 3). The increase of enzyme activity and enzyme protein per unit volume can enhance the comprehensive activity of enzymes [22], which means that the increased cellulase activities in mutant MEA-12 is due to both the improved enzyme activity and enzyme production, and based on data, the former was higher than the latter.
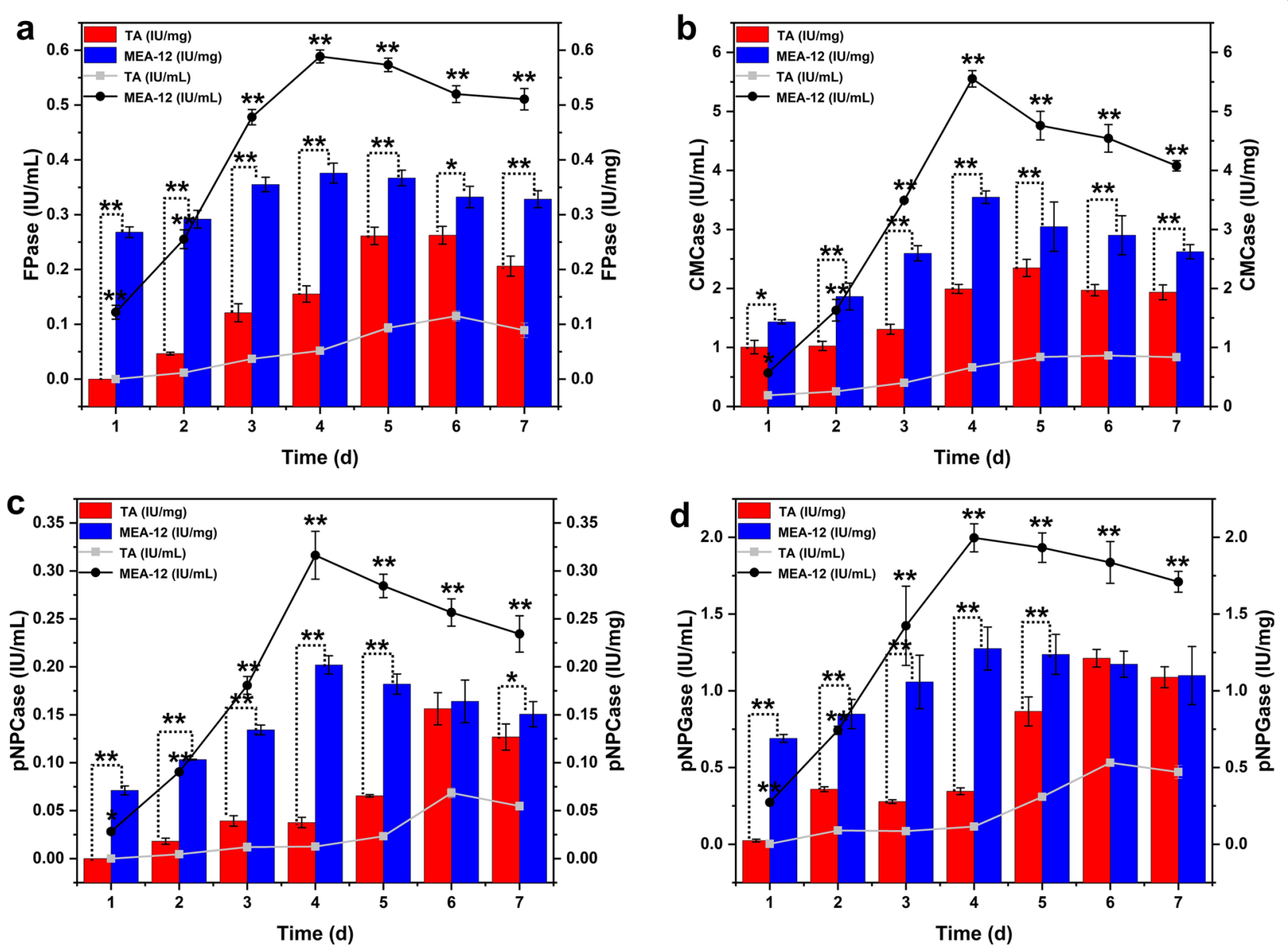

Fig. 3 Activities of FPase, CMCase, pNPCase and pNPGase from TA and MEA-12. "IU/mL" means the specific activities which are calculated based on volume while the "IU/mg" is based on protein mass. Error bars indicate the mean \pm SD of three biological replicates and statistical significance was calculated by Student's $t$ test $*^{*}(p<0.05)$ and $\left.{ }^{* *}(p<0.01)\right)$ 
Glucose tolerance of the mutant MEA-12

Carbon catabolite repression (CCR) is widely present in microorganism growth process [23]. When the medium contains simple carbon sources such as glucose, microorganisms preferentially use simple carbon sources and their metabolites will inhibit other non-fast-acting carbon source metabolism related gene expression and protein activity [24, 25]. Also, the inhibition of cellulase production by glucose is a common characteristic in Trichoderma [26]. However, there is no report on whether CCR exists in T. afroharzianum, as far as we know. In this study, activities of all four enzymes from parental strain TA were profoundly inhibited with the increase of glucose concentration (Fig. 4), which meant that the CCR was also present in T. afroharzianum. On the other hand, no significant inhibition of FPase, CMCase, pNPCase and pNPGase from mutant MEA12 occurred by glucose reached up to $20 \mathrm{mM}$ (Fig. 4). It was due to the increase in concentration of metabolic repressor in screening medium (SM1-3) during mutagenesis, allowing the mutant to gradually adapt to the highconcentration glucose culture environment. At the same time, it explained the reason for high production of mutant MEA-12 on an apparent level (glucose tolerance) and further illustrated the effectiveness of the ALE with high sugar stress.

\section{Total extracellular proteins and transcription levels of major cellulase structural genes and transcription} factors

To further analyze the differences in protein composition in different enzymes, the proteins secreted by TA, MEA12, T. reesei Rut-C30 (TR) and Novozymes were compared by SDS-PAGE analysis. The composition of two protein mixtures in parent strain TA and mutant MEA12 was similar, but the relative concentrations of different
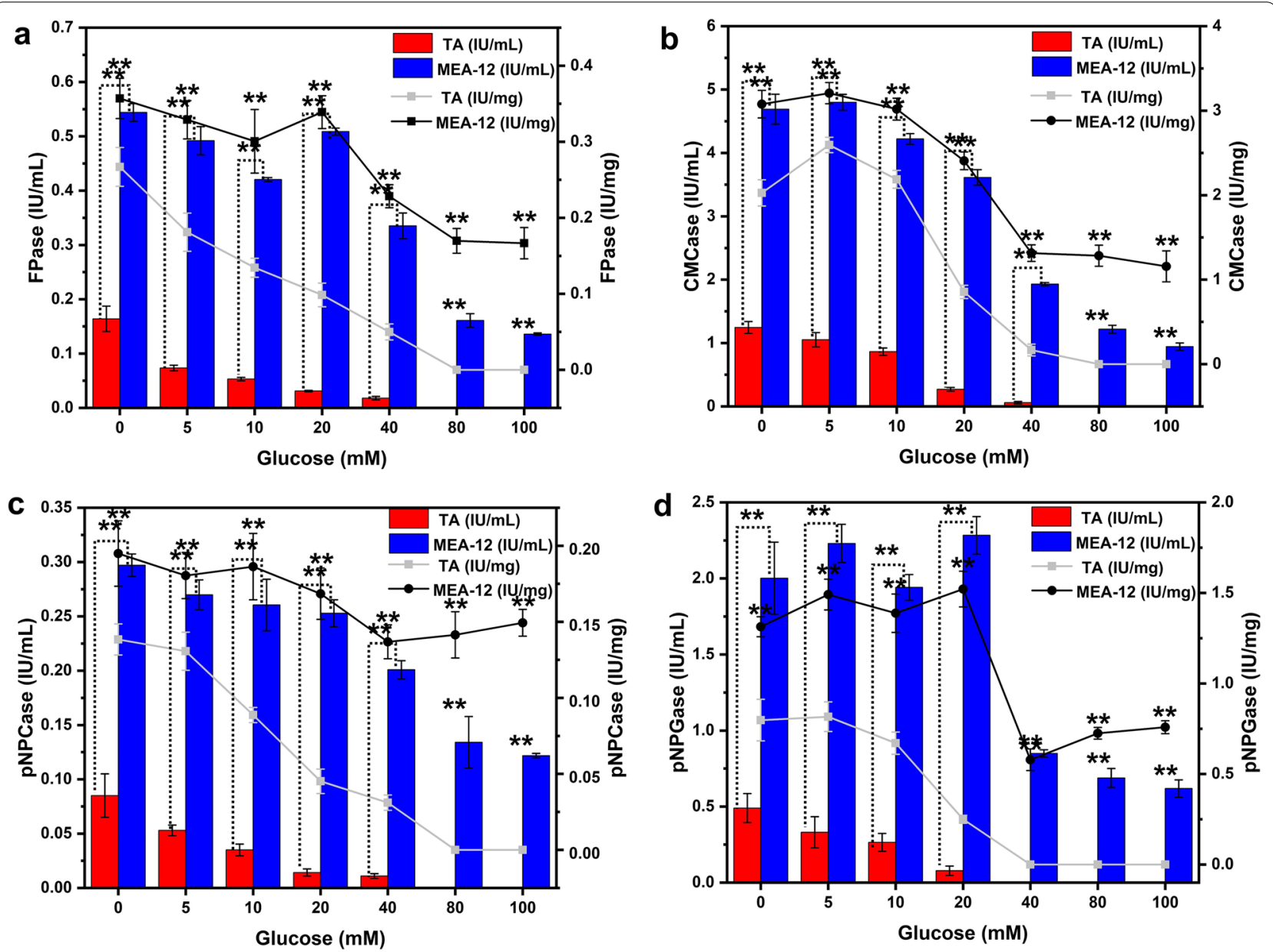

Fig. 4 Cellulase activities of TA and MEA-12 using inducing medium supplemented with different content of glucose. "IU/mL" means the specific activities which are calculated based on volume while the "IU/mg" is based on protein mass. Error bars indicate the mean \pm SD of three biological replicates and statistical significance was calculated by Student's $t$ test ${ }^{*}(p<0.05)$ and ** $\left.(p<0.01)\right)$ 
components were significantly different. Specifically, the band corresponding to cellulose-degrading enzyme cellobiohydrolase II (CBH II) ( $60 \mathrm{kDa}$, red arrow) [27] in MEA-12 was denser than TA (Fig. 5a). Therefore, MEA12 apparently produced more $\mathrm{CBH}$ II than TA. CBH II can release glucose from the non-reducing end of cellulose, and it works in concert with $\beta$-glucosidase to generate a new non-reducing end in cellulose chain, thereby improving the efficiency of hydrolysis [3]. In addition, the crude enzyme secreted by MEA-12 had achieved a good balance between different synergistic cellulase enzymes, which can degrade cellulose effectively. Furthermore, the enzyme band of $T$. reesei Rut-C30 was slightly thicker than that of MEA-12. This matched the superior power of the cellulase production model strain T. reesei Rut-C30. T. reesei Rut-C30 has been developed for decades and is currently an industrial strain with a relatively complete cellulase system [28]. The comparable protein secretion level between MEA-12 and T. reesei Rut-C30 and the higher production of $\beta$-glucosidase by MEA-12 (Table 2) suggest its great potential for biotechnological application, especially for lignocellulose biomass hydrolysis.

In addition, transcriptional levels of major cellulase genes (cbh1, cbh2, eg1, eg2 and bgl1) and transcriptional regulatory genes (xyr1, cre1, ace1 and ace3) were measured by RT-qPCR analysis. Compared to the parental strain TA, the transcriptional levels of the major cellulase genes (cbh1, cbh2, eg1, eg2, and bgl1) in MEA-12 were all significantly up-regulated in both $24 \mathrm{~h}$ and $48 \mathrm{~h}$ induction and the relative expression reached 2.48, 4.54, 1.61, 7.16 and 3.23 at 48 h, respectively (Fig. 5b). Both Xyr1 and Ace3 control the inducible expression of cellulase genes in T. harzianum and T. reesei, respectively $[29,30]$. Furthermore, T. afroharzianum is closely related to the above two strains [31]. After mutagenesis of the parental strain TA, the up-regulated transcription levels of $x y r 1$ and ace 3 in MEA-12 (Fig. 5b) can partly explain its increased cellulase production. The transcription level of cre 1 at $24 \mathrm{~h} / 48 \mathrm{~h}$ in MEA-12 was higher than that of TA, which was due to the high-yield cellulase can release more glucose from the carbon source in a short time and
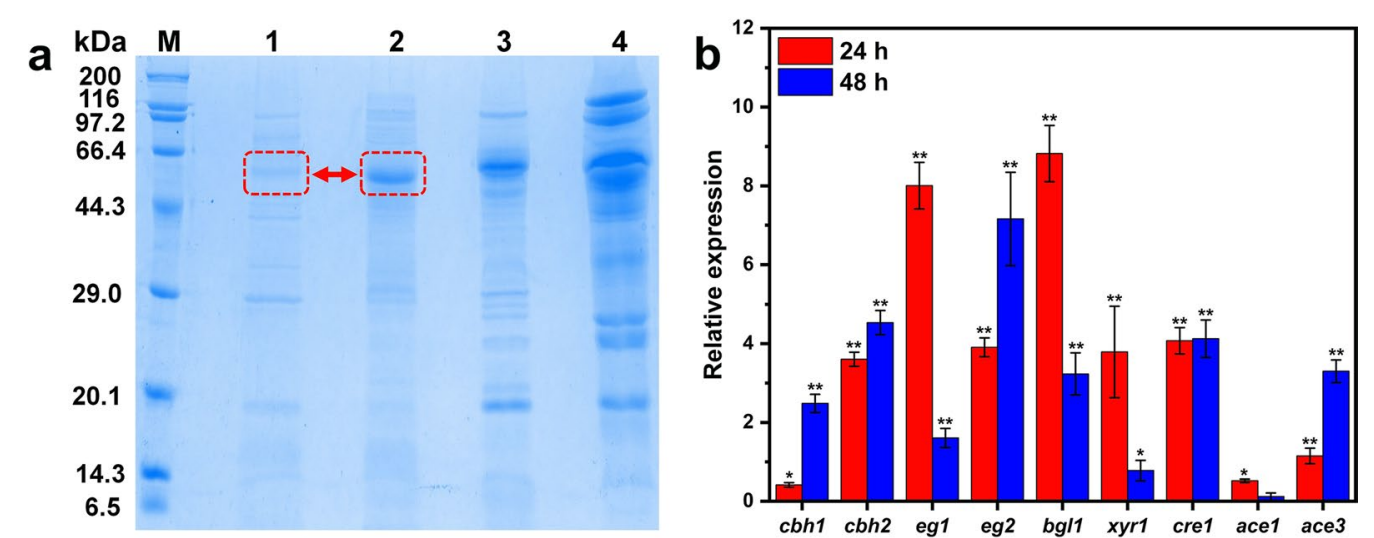

Fig. 5 SDS-PAGE of enzyme produced by TA, MEA-12, T. reesei Rut-C30, Novozymes a and expression levels of the genes encoding major cellulase and transcription regulators in MEA-12 (b). Lane 1:TA; Lane 2: MEA-12; Lane 3: T. reesei Rut-C30; Lane 4: Novozymes. The actin gene was used as the endogenous control. Error bars indicate the mean \pm SD of three biological replicates and statistical significance was calculated by Student's $t$ test ${ }^{*}$ $(p<0.05)$ and $\left.{ }^{* *}(p<0.01)\right)$

Table 2 Comparison of $\beta$-glucosidase activity of T. afroharzianum mutant MEA-12 with other microbial strains in the literature

\begin{tabular}{|c|c|c|c|}
\hline Microorganisms & Cellulose substrate & $\beta$-glucosidase activity (IU/mL) & References \\
\hline T. reesei QM6a & Microcrystalline cellulose and wheat bran & 0.15 & [33] \\
\hline T. reesei QM9414 & Microcrystalline cellulose and wheat bran & 0.51 & [33] \\
\hline T. reesei Rut-C30 & Microcrystalline cellulose & 0.42 & [34] \\
\hline T. orientalis EU7-22 & Miscanthus cellulose & 0.49 & [35] \\
\hline T. harzianum & Carboxymethyl cellulose & 0.26 & [36] \\
\hline T. harzianum LZ117 & Microcrystalline cellulose and wheat bran & 2.78 & {$[33]$} \\
\hline T. afroharzianum & Microcrystalline cellulose & 0.52 & This study \\
\hline T. afroharzianum MEA-12 & Microcrystalline cellulose & 2.17 & This study \\
\hline
\end{tabular}


results in carbon metabolic repression (Fig. 5b). Ace1 is a transcription repressor that regulates cellulase production in Trichoderma spp., so the lower level of ace1 transcription can improve the cellulase production [32]. However, the transcription level of ace1 in MEA-12 was higher than that of TA after the $24 \mathrm{~h} / 48 \mathrm{~h}$ induction. Fortunately, this increase was not obvious (24 h: $0.01<p<$ 0.05/48 h: $p>0.05$ ).

Since the whole genome analysis of $T$. afroharzianum has not been completed (https://www.ncbi.nlm.nih. gov/bioproject/PRJNA776045/), in the future, comparative genomics can be used to analyze the mechanism of mutants' high cellulase production. Further improve cellulase production of the target strain through the inverse metabolic engineering.

\section{Hydrolytic analysis of different pretreated biomasses with crude enzyme produced by mutant MEA-12}

Cornstalk, bamboo and reed as non-wood and non-food biomass materials, depending on their different fiber processing technology, can turn them into glucose and other wide range of products, which has been widely used in China, the United States and some of European countries [37]. Currently, T. reesei Rut-C30 (TR) is recognized as an excellent cellulase-producing strain. However, its lower $\beta$-glucosidase activity causes cellobiose to accumulate, which affects the efficiency of enzymatic hydrolysis and saccharification, thereby reducing the yield of ethanol [28]. Therefore, the above three kinds of biomass were chosen to evaluate the potential of cellulase produced by MEA-12, with TR as control. Furthermore, causing the high $\beta$-glucosidase (pNPGase) activity of MEA-12 (Table 2), the mixed cellulase of MEA-12 and TR was used to hydrolyze lignocellulose, which can compensate for the defects of cellulase produced by TR.

As shown in Fig. 6a-c, when cornstalk pulp was used as substrate, the enzymatic hydrolysis efficiency of compound cellulase was the highest when pNPGase/FPase ("IU/mL": "IU $/ \mathrm{mL} ")=1.2$, while bamboo pulp was 1.4 and reed pulp was 1.6. This phenomenon may be attributed to the level of non-cellulose content in the substrate (cornstalk<bamboo<reed). The higher non-cellulose content hindered the process of enzymatic saccharification. Therefore, more $\beta$-glucosidase was needed to accelerate enzymatic hydrolysis and convert disaccharides into monosaccharides. When enzyme load reached 20 FPU/g, the efficiency of enzymatic hydrolysis was $81.1 \%$ and then rose slowly, which also occurred in bamboo and reed. It was because the enzymatic effect will be saturated when concentration of the enzyme was much higher than the substrate [38]. Therefore, for economic consideration, $20 \mathrm{FPU} / \mathrm{g}$ will be used as the final added amount of compound cellulase in processing substrates.
Analysis of enzymatic hydrolysis reactions revealed that the hydrolytic efficiency of the crude MEA-12 enzyme for converting cornstalk pulp into glucose was slightly lower than the TR enzyme (degree of hydrolysis: $35.4 \%$ and $40.7 \%$ after $48 \mathrm{~h}$, respectively Fig. $6 \mathrm{~g}$ ). In contrast, with two other biomasses as the substrate, the degree of hydrolysis was $45.2 \%$ ( bamboo) $/ 50.7 \%$ (reed) and $35.6 \%$ (bamboo)/39.4\% (reed) after $48 \mathrm{~h}$, with the MEA-12 and TR enzymes, respectively (Fig. 6h, i). Additionally, with cornstalk pulp as the substrate, the enzymatic hydrolysis efficiency of compound cellulase reached $80.2 \%$ after $48 \mathrm{~h}$, which was slightly higher than commercial cellulase (77.9\%), and it was also 1.97-2.27 times than that of single enzyme treatment (Fig. 6g). The compound cellulase exhibited strong biomass hydrolysis ability, which was also present in bamboo and reed. Finally, when hydrolyzing cornstalk, the hydrolysis efficiency of compound cellulase was up to $85.0 \%$ after $96 \mathrm{~h}$ (91.9\% in bamboo and $97.6 \%$ in reed). It was close to or even higher than the treatment effect of commercial cellulase $(82.6 \%$ in cornstalk, 94.1\% in bamboo and 95.4\% in reed) (Fig. 6g-i).

The enzymatic hydrolysis efficiency of pretreated biomass hinges on the composition of the enzyme mixture [39]. After mutagenesis of wild-type TA, the protein composition of cellulase changed (For example, increasing the ratio of $\mathrm{CBH}$ II, mentioned before) (Fig. 5a), which changed the diversity of enzymatic cocktails. Therefore, the biomass hydrolysis efficiency of the crude enzyme produced by the mutant MEA-12 had been greatly improved. Even efficiency during hydrolysis of bamboo and reed pulp exceeded the model strain TR, showing the mutant MEA-12 has high great potential for industrial application. At present, the commercial cellulase solution is mainly composed of cellulase derived from Trichoderma and Aspergillus [40]. However, the composition of cellulase from different genera is different. MEA-12, which is also of the genus Trichoderma, is possible to co-culture with $T$. reesei and provides a better choice for the compounding of commercial cellulase.

\section{Conclusion}

In this study, a T. afroharzianum mutant strain, MEA12 , was isolated and resulted in 4.33, 6.37, 4.92 and 4.15 times increase in FPase, CMCase, pNPCase and pNPGase, respectively, with higher insensitivity for catabolite repression. Crude enzyme from $T$. afroharzianum MEA-12 showed high enzymatic hydrolysis efficiency against common biomasses (cornstalk, bamboo, reed), when combined with cellulase from $T$. reesei Rut-C30. Furthermore, the factors that improved cellulase production by MEA- 12 were clarified. This study confirmed that compound mutagenesis combined with ALE method was an effective tool to increase the cellulase production of 


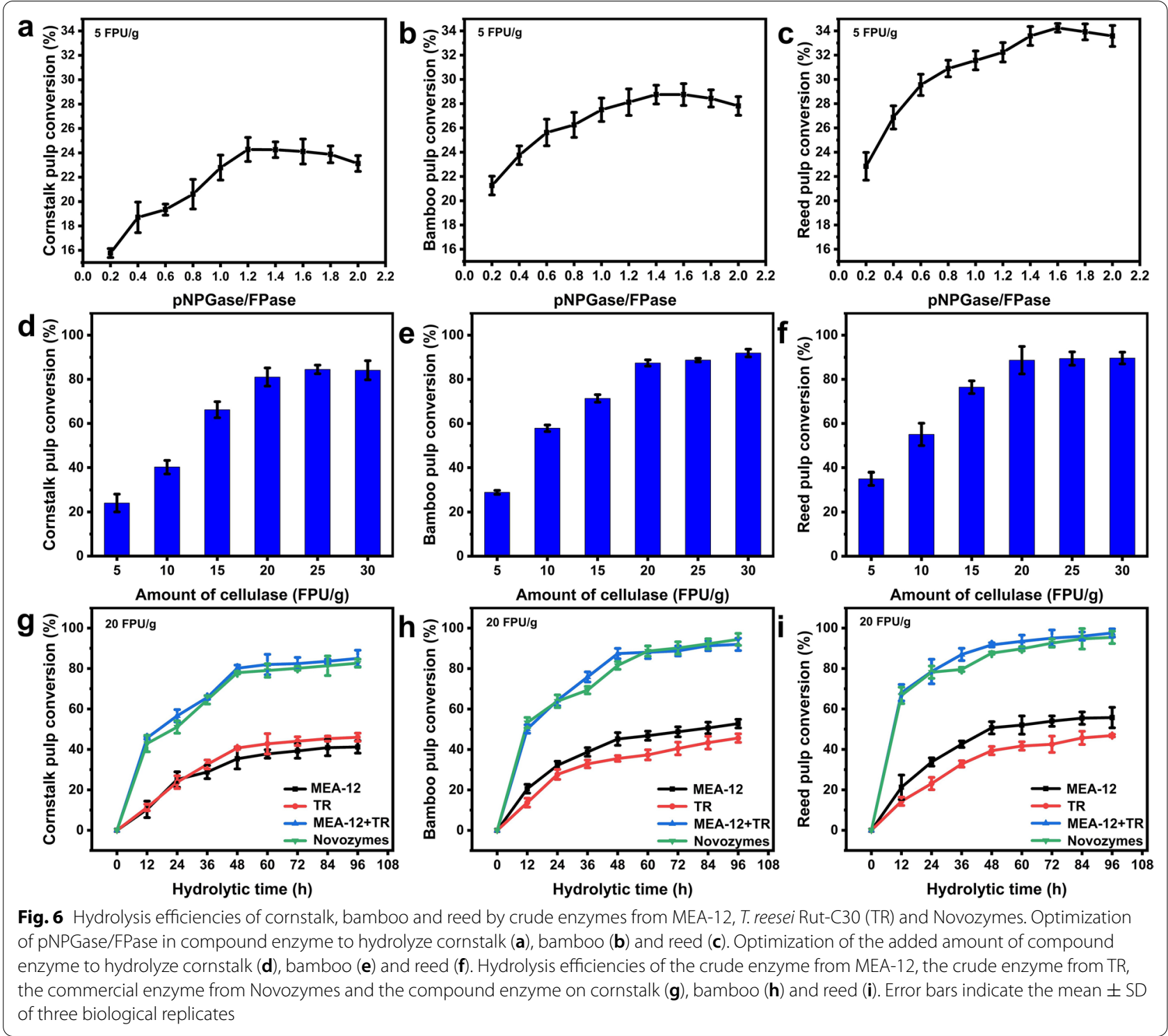

filamentous fungi and provided a new choice for processing of bioresources in the future.

\section{Methods}

\section{Microorganisms and culture conditions}

The T. afroharzianum (CICC 40189) and T. reesei RutC30 (CICC 13052) were obtained from the China Center of Industrial Culture Collection (CICC). Fresh spores were collected from $T$. afroharzianum and T. reesei RutC30 cultured on potato dextrose agar (PDA) plates for 4 days and 6 days, respectively.

For mutagenesis, T. afroharzianum $\left(1 \times 10^{7}-1 \times 10^{8}\right.$ spores) were diluted and spread on the screening medium (SM), cultured at $30{ }^{\circ} \mathrm{C}$ for 4 days. The SM contains $2.0 \mathrm{~g} / \mathrm{L} \quad \mathrm{KH}_{2} \mathrm{PO}_{4}, 1.4 \mathrm{~g} / \mathrm{L} \quad\left(\mathrm{NH}_{4}\right)_{2} \mathrm{SO}_{4}$,
$0.75 \mathrm{~g} / \mathrm{L}$ peptone, $0.3 \mathrm{~g} / \mathrm{L}$ urea, $0.3 \mathrm{~g} / \mathrm{L} \mathrm{CaCl}_{2}, 0.3 \mathrm{~g} / \mathrm{L}$ $\mathrm{MgSO}_{4} \cdot 7 \mathrm{H}_{2} \mathrm{O}, 0.25 \mathrm{~g} / \mathrm{L}$ yeast extract, $2.0 \mathrm{~g} / \mathrm{L}$ Triton $\mathrm{X}-100,20.0 \mathrm{~g} / \mathrm{L}$ agar and $1.0 \mathrm{~mL} / \mathrm{L}$ trace element nutrient solution [41]. The trace element nutrient solution contains $5.0 \mathrm{~g} / \mathrm{L} \mathrm{FeSO}_{4} \cdot 7 \mathrm{H}_{2} \mathrm{O}, 2.0 \mathrm{~g} / \mathrm{L} \mathrm{CoCl}_{2} \cdot 6 \mathrm{H}_{2} \mathrm{O}, 1.6 \mathrm{~g} / \mathrm{L}$ $\mathrm{MnSO}_{4} \cdot 4 \mathrm{H}_{2} \mathrm{O}, 1.4 \mathrm{~g} / \mathrm{L} \mathrm{ZnSO}_{4} \cdot 7 \mathrm{H}_{2} \mathrm{O}$ [42]. The SM was supplemented with $10.0 \mathrm{~g} / \mathrm{L}$ Carboxymethyl Cellulose$\mathrm{Na}$ (CMC-Na) and 5.0 g/L 2-deoxyglucose (SM1); $3.0 \mathrm{~g} / \mathrm{L}$ esculin, $0.5 \mathrm{~g} / \mathrm{L}$ ferric citrate and $10.0 \mathrm{~g} / \mathrm{L} 2$-deoxyglucose (SM2); $10.0 \mathrm{~g} / \mathrm{L}$ Cellulose microcrystalline (MCC) and $50.0 \mathrm{~g} / \mathrm{L} 2$-deoxyglucose (SM3).

For fermentation of enzyme production, T. afroharzianum $\left(1 \times 10^{8}\right.$ spores $)$ and T. reesei Rut-C30 $\left(1 \times 10^{8}\right.$ spores) were cultured in preculture medium $(20.0 \mathrm{~g} / \mathrm{L}$ yeast extract, $15.0 \mathrm{~g} / \mathrm{L}$ glucose, $6.0 \mathrm{~g} / \mathrm{L} \mathrm{KH}_{2} \mathrm{PO}_{4}, 2.5 \mathrm{~g} / \mathrm{L}$ 
$\left(\mathrm{NH}_{4}\right)_{2} \mathrm{SO}_{4}, 1.0 \mathrm{~g} / \mathrm{L} \mathrm{CaCl} 2,0.8 \mathrm{~g} / \mathrm{L} \mathrm{MgSO}_{4} \cdot 7 \mathrm{H}_{2} \mathrm{O}, 2.0 \mathrm{~g} / \mathrm{L}$ tween $80,1.0 \mathrm{~mL} / \mathrm{L}$ trace element nutrient solution, $\mathrm{pH}$ 4.8), at $180 \mathrm{rpm}$ and $30^{\circ} \mathrm{C}$, for 2 days, respectively. Then, it was inoculated into fermentation medium $(10.0 \mathrm{~g} / \mathrm{L}$ lactose, $10.0 \mathrm{~g} / \mathrm{L} \mathrm{MCC,} 12.0 \mathrm{~g} / \mathrm{L}$ Spray Drying Corn Steep Liquor, $1.5 \mathrm{~g} / \mathrm{L}\left(\mathrm{NH}_{4}\right)_{2} \mathrm{SO}_{4}, 1.4 \mathrm{~g} / \mathrm{L} \mathrm{CaCl}_{2}, 1.2 \mathrm{~g} / \mathrm{L}$ $\mathrm{MgSO}_{4} \cdot 7 \mathrm{H}_{2} \mathrm{O}, 2.0 \mathrm{~g} / \mathrm{L}$ tween $80,1.0 \mathrm{~mL} / \mathrm{L}$ trace element solution, $\mathrm{pH} 4.8)$ in $10 \%(\mathrm{v} / \mathrm{v})$ inoculum size at $180 \mathrm{rpm}$ and $30{ }^{\circ} \mathrm{C}$, for 4 days. Centrifuge at $10,000 \times g$ for $15 \mathrm{~min}$ and collect the supernatant for measuring enzyme activity and enzymatic hydrolysis of bamboo pulp.

For RT-qPCR analyses, T. afroharzianum $\left(1 \times 10^{8}\right.$ spores) were cultured in preculture medium for 2 days, then transferred into fermentation medium, at $180 \mathrm{rpm}$ and $30{ }^{\circ} \mathrm{C}$, for 24 and $48 \mathrm{~h}$. Centrifuge at $12,000 \times g$ for 10 min to collect the mycelia and grind with liquid nitrogen to extract total RNA.

All the above media were sterilized at $121{ }^{\circ} \mathrm{C}$ for $20 \mathrm{~min}$ before use.

\section{Mutagenesis}

MNNG (0.1 g) was dissolved in $1 \mathrm{~mL}$ acetone to prepare $10 \%$ solution for treatment. The spore suspension $(970 \mu \mathrm{L})$ and $10 \%$ MNNG solution $(30 \mu \mathrm{L})$ placed in a constant temperature shaker, shaking at $30{ }^{\circ} \mathrm{C}$ and $180 \mathrm{rpm}$, for 0-90 min, to determine the optimum treatment time. After the treatment of mutagenesis, the supernatant was discarded after the centrifugation at $12,000 \times g$ for $3 \mathrm{~min}$, and the new spore suspension was prepared by washing and the precipitation with $1 \%$ normal saline for 2 times. After the dilution treatment, postmutagenesis spore suspension was spread on the SM1 and cultured at $30{ }^{\circ} \mathrm{C}$ for 4 days. Strain with apparent positive mutation, which the ratio of transparent circle diameter to colony diameter was higher than that of the parental strain.

For EMS treatment, 50\% EMS solution was prepared by mixing EMS and acetone at the volume ratio of 1:1. The spore suspension $(970 \mu \mathrm{L})$ and $50 \%$ EMS solution $(30 \mu \mathrm{L})$ were mixed in a constant temperature shaker, shaking at $30{ }^{\circ} \mathrm{C}$ and $180 \mathrm{rpm}$, for $0-90 \mathrm{~min}$, to determine the optimum treatment time. After the treatment of mutagenesis, the supernatant was discarded by centrifugation at $12,000 \times g$ for $3 \mathrm{~min}$, and the new spore suspension was prepared by washing and precipitation with $1 \%$ normal saline for 2 times. After the dilution treatment, postmutagenesis spore suspension was spread on the SM2 and cultured at $30{ }^{\circ} \mathrm{C}$ for 4 days. Colony that became darker and larger in diameter was selected as the apparent positive mutation strain.

For ARTP treatment, the spore suspension $(10 \mu \mathrm{L})$ was smeared on the slides and placed in an ARTP-IIS Bio-breeding Machine (Wuxi Tmaxtree Biotechnology
Co., Ltd., China), for $0 \sim 270$ s, to determine the optimum treatment time. After the mutagenesis, the slides were taken out and placed in an EP tube with $1 \mathrm{~mL} 1 \%$ normal saline. After the dilution treatment, post-mutagenesis spore suspension was spread on the SM3 and cultured at $30{ }^{\circ} \mathrm{C}$ for 4 days. Strain with apparent positive mutation was chosen according to the ratio of transparent circle diameter to colony diameter, which was higher than that of the parental strain.

After determining the optimal treatment time $(50 \mathrm{~min}$ by MNNG, 70 min by EMS and $240 \mathrm{~s}$ by ARTP), perform the combined treatment as described above.

\section{Catabolite repression studies}

For catabolite repression studies, add different concentrations of glucose $(0-100 \mathrm{mM})$ to the fermentation medium. Fermentation lasted for 1-7 days and the optimum fermentation time with the highest enzyme activity was recorded for comparison.

\section{Enzyme activity assay}

The supernatant was collected from fermented broth by centrifugation at $10,000 \times g$ for $15 \mathrm{~min}$. Total soluble protein was quantified using the Modified Bradford Protein Assay Kit (Sangon Biotech, China) according to the manufacturer's instructions. FPase and CMCase activities were assayed using the standard method recommended by the International Union of Pure and Applied Chemistry (IUPAC) [43]. pNPCase and pNPGase activities were assayed in a reaction system containing $0.05 \mathrm{M}$ citrate buffer (pH 4.8) and $50 \mathrm{mM}$ pNPC/pNPG (Sigma, USA) and then incubated at $50{ }^{\circ} \mathrm{C}$ for $30 \mathrm{~min}$, respectively [44]. One unit of enzyme activity was defined as the amount of enzyme capable of releasing $1 \mu \mathrm{mol}$ of reducing sugar or pNP per min under the conditions of $50{ }^{\circ} \mathrm{C}$ and $\mathrm{pH} 4.8$. Furthermore, the specific activities $(\mathrm{IU} / \mathrm{mg})=$ Enzyme activity $(\mathrm{IU} / \mathrm{mL})$ / Total soluble protein $(\mathrm{mg} / \mathrm{mL})$. The FPase, CMCase, pNPCase and pNPGase activities represent the total cellulase, endoglucanase, cellobiohydrolase and $\beta$-glucosidase activity, respectively [45].

\section{SDS-PAGE and RT-qPCR}

Proteins secreted by T. afroharzianum and MEA-12 cultured in fermentation medium were collected at the 4th day and analyzed by sodium dodecyl sulfate-polyacrylamide gel electrophoresis (SDS-PAGE).

Culture conditions of the strains used for RT-qPCR were same to those described above. Total RNA was extracted using the RNA pure total RNA rapid extraction kit (Shanghai Hlingene Biological technology Co., Ltd., China) and then cDNA synthesis using the TransScript $^{\circledR}$ One-Step gDNA Removal and cDNA Synthesis SuperMix (TransGen Biotech, China) according to the 
manufacturer's instructions. RT-qPCR primers of the tested genes were designed as described in a previous study (Additional file 1: Table S1), and it was performed using the ChamQ ${ }^{\mathrm{TM}}$ Univerasl SYBR qPCR Master Mix (Vazyme, China) and the QuantStudio ${ }^{\text {TM }}$ real-time PCR system (Thermo Fisher Scientific, USA) according to the manufacturer's instructions. Relative quantification of the tested genes was calculated by using comparative cycle threshold $\left(2^{-\Delta \Delta \mathrm{CT}}\right)$ method. The actin gene was chosen as the endogenous control to normalize the expression levels. All experiments were performed in triplicates.

\section{Enzymatic hydrolysis of pretreated biomass}

Cornstalk pulp (contains $72.7 \%$ cellulose, $20.1 \%$ hemicellulose, $7.2 \%$ others), bamboo pulp (contains $71.9 \%$ cellulose, $21.4 \%$ hemicellulose, $6.7 \%$ others) and reed pulp (contains $66.6 \%$ cellulose, 27.3\% hemicellulose, 6.1\% others) (Additional file 1: Fig. S4) produced by cooking with active oxygen and solid alkali (CAOSA), a novel pretreatment method reported by the authors' group [46]. Raw material (1 kg, dry weight), $\mathrm{MgO}(150 \mathrm{~g})$ and water $(4 \mathrm{~kg})$ were mixed in a spherical digester (designed by authors' group and built by Yantai Keli Chemical Equipment Co., Ltd., China) at an initial oxygen pressure of $2.0 \mathrm{MPa}$ and a temperature of $160{ }^{\circ} \mathrm{C}$ for about $10 \mathrm{~h}$. After the reaction, the solid pulp was filtered and washed with clean water several times. The obtained pulp was used as the substrate for enzymatic saccharification. Under inducing conditions, fermentation was carried out to produce crude enzyme, which was subsequently used for the enzymatic hydrolysis of different biomasses and compared with commercial enzymes $\left(\right.$ Cellic $^{\circledR}$ CTec2 (Novozymes A/S, Damark)). Enzymatic hydrolysis was performed in $0.05 \mathrm{M}$ citrate buffer $(\mathrm{pH} 4.8)$ at $2.0 \%$ (g: $\mathrm{mL}$ ) substrate consistency and then incubated at $50{ }^{\circ} \mathrm{C}$ and $180 \mathrm{rpm}$ for $96 \mathrm{~h}$ [47]. The enzyme loading was 5 FPU/g substrate (dry weight), which would be optimized later. The hydrolysates were sampled every $12 \mathrm{~h}$, boiled for $5 \mathrm{~min}$ to inactivate the enzyme, and then centrifuged at $10,000 \times \mathrm{g}$. Glucose in the supernatant was determined using an SBA-40E Bio-sensor (Jinan Yanhe Biotechnology Co., Ltd., China). Biomass conversion (\%) $=($ Glucose $(\mathrm{g} / \mathrm{L}) \times$ Enzymatic hydrolysis system $(L) \times 0.9) /($ Substrate $(g) \times$ Cellulose content $(\%))$.

\section{Statistical analysis}

All the experiments values presented in figures are mean \pm SD calculated with Excel 2019. All experiments were conducted in triplicate and all the multiple comparison tests were performed with Student's $t$ test (significance levels: * $(p<0.05)$ and $* *(p<0.01))$.

\section{Abbreviations}

CCR: Carbon catabolite repression; MNNG: N-methyl-N'-nitro-N-nitrosoguanidine; EMS: Ethyl Methanesulfonate; ARTP: Atmospheric and Room Temperature Plasma; ALE: Adaptive laboratory evolution; CAOSA: Cooking with active oxygen and solid alkali; SM: Screening medium; SDS-PAGE: Sodium dodecyl sulfate-polyacrylamide gel electrophoresis; RT-qPCR: Real-time reverse transcription quantitative PCR; EGs: Endoglucanases; CBHs: Cellobiohydrolases; BGs: $\beta$-Glucosidases; TA: T. afroharzianum; TR: T. reesei Rut-C30.

\section{Supplementary Information}

The online version contains supplementary material available at https://doi. org/10.1186/s13068-021-02072-z.

Additional file 1: Table S1. Primers used for RT-qPCR. Figure S1. Enzyme activity of MNNG mutagenesis re-screening. a diameter ratio (hydrolysis circle diameter/strain diameter) of TA and its mutants, $\mathbf{b}$ FPase activities of TA and its mutants, c CMCase activities of TA and its mutants. Figure S2. Enzyme activity of EMS mutagenesis re-screening. a FPase activities of M-84 and its mutants, $\mathbf{b}$ CMCase activities of M-84 and its mutants, $\mathbf{c}$ pNPCase activities of M-84 and its mutants, $\mathbf{d}$ pNPGase activities of M-84 and its mutants. Figure S3. Enzyme activity of ARTP mutagenesis rescreening. a FPase activities of ME-10 and its mutants, $\mathbf{b}$ CMCase activities of ME-10 and its mutants, $\mathbf{c}$ pNPCase activities of ME-10 and its mutants, d pNPGase activities of ME-10 and its mutants. Figure S4. Common biomasses after pretreatment for hydrolysis.

\section{Acknowledgements}

This work was supported by National Natural Science Foundation of China (No. 21978248 \& 21676223) and Natural Science Foundation of Fujian Province of China (No.2019J06005). Moreover, the authors gratefully acknowledge the ARTP mutagenesis related equipment support from the Scientific Instruments Sharing Platform, Third Institute of Oceanography, Ministry of Natural Resources, and the RT-qPCR analysis related equipment support from the Centre of Major Equipment and Technology (COMET), State Key Laboratory of Marine Environmental Science (Xiamen University).

\section{Authors' contributions}

ZQP and XHZ conceived and wrote the manuscript. ZQP, CL, YL, SSW, LHG, $J L, S L Y$ performed experiments. XHZ and LL revised and approved the manuscript. All authors read and approved the final manuscript.

\section{Funding}

National Natural Science Foundation of China (No. 21978248 \& 21676223) and Natural Science Foundation of Fujian Province of China (No.2019J06005).

\section{Availability of data and materials}

All data and materials are available in the main text and supporting information.

\section{Declarations}

Ethics approval and consent to participate Not applicable.

\section{Consent for publication}

All the authors have read and approved the manuscript before the submission to Biotechnology for Biofuels.

\section{Competing interests}

The authors declare that there are no conflicts of interest.

\section{Author details}

${ }^{1}$ College of Energy, Xiamen University, Xiamen 361102, China. ${ }^{2}$ Fujian Engineering and Research Centre of Clean and High-Valued Technologies for Biomass, Xiamen 361102, China. ${ }^{3}$ Xiamen Key Laboratory of Clean and HighValued Utilization for Biomass, Xiamen 361102, China. 
Received: 7 September 2021 Accepted: 10 November 2021

Published online: 22 November 2021

\section{References}

1. Kothari N, Bhagia S, Pu YQ, Yoo CG, Li M, Venketachalam S, et al. The effect of switchgrass plant cell wall properties on its deconstruction by thermochemical pretreatments coupled with fungal enzymatic hydrolysis or Clostridium thermocellum consolidated bioprocessing. Green Chem. 2020;22(22):7924-45.

2. Vaid S, Sharma S, Bajaj BK. Chemo-enzymatic approaches for consolidated bioconversion of Saccharum spontaneum biomass to ethanolbiofuel. Bioresource Technol. 2021;329:124898.

3. Payne CM, Knott BC, Mayes HB, Hansson H, Himmel ME, Sandgren M, et al. Fungal Cellulases. Chem Rev. 2015;115(3):1308-448.

4. Vanzyl WH. A study of the cellulases produced by 3 mesophilic actinomycetes grown on bagasse as substrate. Biotechnol Bioeng. 1985;27(9):1367-73.

5. Liu GD, Qu YB. Engineering of filamentous fungi for efficient conversion of lignocellulose: Tools, recent advances and prospects. Biotechnol Adv. 2019;37(4):519-29.

6. Yu Q, Li Y, Wu B, HuW, He M, Hu G. Novel mutagenesis and screening technologies for food microorganisms: advances and prospects. Appl Microbiol Biotechnol. 2020;104(4):1517-31

7. Wang Y, Ho SH, Yen HW, Nagarajan D, Ren NQ, Li SF, et al. Current advances on fermentative biobutanol production using third generation feedstock. Biotechnol Adv. 2017:35(8):1049-59.

8. Jain L, Agrawal D. Rational approach for mutant selection of Talaromyces verruculosus IIPC 324 secreting biofuel cellulases-Assessing saccharification potential. Ind Crop Prod. 2018;114:93-7.

9. Jiang BL, Wang SY, Wang YC, Chen JH, Li WJ, Liu J, et al. A high-throughput screening method for breeding Aspergillus niger with C-12(6+) ion beamimproved cellulase. Nucl Sci Tech. 2017;28(1):1.

10. Gao F, Hao ZZ, Sun XH, Qin LN, Zhao T, Liu WQ, et al. A versatile system for fast screening and isolation of Trichoderma reesei cellulase hyperproducers based on DsRed and fluorescence-assisted cell sorting. Biotechnol Biofuels. 2018;11:261

11. Wang HW, Zhai LL, Geng AL. Enhanced cellulase and reducing sugar production by a new mutant strain Trichoderma harzianum EUA20. J Biosci Bioeng. 2020;129(2):242-9.

12. Liu F, Wang ZS, Manglekar RR, Geng AL. Enhanced cellulase production through random mutagenesis of Talaromyces pinophilus OPC4-1 and fermentation optimization. Process Biochem. 2020:90:12-22.

13. Kun RS, Gomes ACS, Hilden KS, Cerezo SS, Makela MR, de Vries RP. Developments and opportunities in fungal strain engineering for the production of novel enzymes and enzyme cocktails for plant biomass degradation. Biotechnol Adv. 2019;37(6):107361.

14. Zhang $X$, Zhang XF, Li HP, Wang LY, Zhang C, Xing XH, et al. Atmospheric and room temperature plasma (ARTP) as a new powerful mutagenesis tool. Appl Microbiol Biot. 2014;98(12):5387-96.

15. Wu T, Liu JF, Li MJ, Zhang G, Liu L, Li X, et al. Improvement of sabinene tolerance of Escherichia coli using adaptive laboratory evolution and omics technologies. Biotechnol Biofuels. 2020;13(1):79.

16. Wu Y, Jameel A, Xing XH, Zhang C. Advanced strategies and tools to facilitate and streamline microbial adaptive laboratory evolution. Trends Biotechnol. In Press, Corrected Proof, Available online 3 May 2021. https:// doi.org/10.1016/j.tibtech.2021.04.002

17. Ramamoorthy NK, Sambavi TR, Renganathan S. Assessment of fed-batch strategies for enhanced cellulase production from a waste lignocellulosic mixture. Biochem Eng J. 2019;152:107387.

18. Jing $L$, Zhao $S$, Xue JL, Zhang Z, Yang $Q$, Xian $L$, et al. Isolation and characterization of a novel Penicillium oxalicum strain Z1-3 with enhanced cellobiohydrolase production using cellulase-hydrolyzed sugarcane bagasse as carbon source. Ind Crop Prod. 2015;77:666-75.

19. Kao MR, Kuo HW, Lee CC, Huang KY, Huang TY, Li CW, et al. Chaetomella raphigera beta-glucosidase D2-BGL has intriguing structural features and a high substrate affinity that renders it an efficient cellulase supplement for lignocellulosic biomass hydrolysis. Biotechnol Biofuels. 2019;12:258.
20. Sun JD, Wang Y, Wu B, Bai ZZ, He BF. Enhanced production of D-lactic acid by Sporolactobacillus sp Y2-8 mutant generated by atmospheric and room temperature plasma. Biotechnol Appl Bioc. 2015;62(2):287-92.

21. Li XQ, Xia JL, Zhu XY, Bilal M, Tan ZB, Shi H. Construction and characterization of bifunctional cellulases: Caldicellulosiruptor-sourced endoglucanase, CBM, and exoglucanase for efficient degradation of lignocellulose. Biochem Eng J. 2019;151:107363.

22. Claassen C, Gerlach T, Rother D. Stimulus-responsive regulation of enzyme activity for one-step and multi-step syntheses. Adv Synth Catal. 2019;361(11):2387-401.

23. Li TG, Zhang C, Yang KL, He JZ. Unique genetic cassettes in a Thermoanaerobacterium contribute to simultaneous conversion of cellulose and monosugars into butanol. Sci Adv. 2018;4(3):e1701475.

24. Lin YM, Chen Y, Li QH, Tian XW, Chu J. Rational high-throughput screening system for high sophorolipids production in Candida bombicola by coutilizing glycerol and glucose capacity. Bioresour Bioprocess. 2019:6:17.

25. Zhang C, Li S, Ho SH. Converting nitrogen and phosphorus wastewater into bioenergy using microalgae-bacteria consortia: a critical review. Bioresour Technol. 2021;342:126056.

26. Chandra M, Kalra A, Sangwan NS, Gaurav SS, Darokar MP, Sangwan RS. Development of a mutant of Trichoderma citrinoviride for enhanced production of cellulases. Bioresource Technol. 2009;100(4):1659-62.

27. Hu G, Heitmann JA, Rojas OJ, Pawlak JJ, Argyropoulos DS. Monitoring cellulase protein adsorption and recovery using SDS-PAGE. Ind Eng Chem Res. 2010;49(18):8333-8.

28. Pang AP, Wang HY, Zhang FN, Hu X, Wu FG, Zhou ZH, et al. High-dose rapamycin exerts a temporary impact on $T$. reesei RUT-C30 through gene trFKBP12. Biotechnol Biofuels. 2021;14(1):77.

29. Li JX, Zhang F, Jiang DD, Li J, Wang FL, Zhang Z, et al. Diversity of cellulase-producing filamentous fungi from Tibet and transcriptomic analysis of a superior cellulase producer Trichoderma harzianum LZ117. Front Microbiol. 2020;11:1617.

30. Zhang JJ, Chen YM, Wu C, Liu P, Wang W, Wei DZ. The transcription factor ACE3 controls cellulase activities and lactose metabolism via two additional regulators in the fungus Trichoderma reesei. J Biol Chem. 2019;294(48):18435-50

31. Haouhach S, Karkachi N, Oguiba B, Sidaoui A, Chamorro I, Kihal M, et al. Three new reports of Trichoderma in Algeria: T. atrobrunneum, (South) T. longibrachiatum (South), and T. afroharzianum (Northwest). Microorganisms. 2020;8(10):1455.

32. Fang CJ, Chen XY. Potential biocontrol efficacy of Trichoderma atroviride with cellulase expression regulator acel gene knock-out. 3 Biotech. 2018;8(7):302

33. Li JX, Zhang F, Li J, Zhang Z, Bai FW, Chen J, et al. Rapid production of lignocellulolytic enzymes by Trichoderma harzianum LZ117 isolated from Tibet for biomass degradation. Bioresource Technol. 2019;292:122063.

34. Meng QS, Zhang F, Liu CG, Zhao XQ, Bai FW. Identification of a novel repressor encoded by the putative gene ctfl for cellulase biosynthesis in Trichoderma reesei through artificial zinc finger engineering. Biotechnol Bioeng. 2020;117(6): 1747-60.

35. Ali N, Liu J. Construction of novel Trichoderma orientalis EU7-22, strain with improved $\beta$-glucosidase activity by cellobiohydrolase I promotor optimization from Trichoderma reesei. Biocatal Agric Biotechnol. 2019;20:101223.

36. Melo IS, Faull JL, Graeme-Cook KA. Relationship between in vitro cellulase production of uv-induced mutants of Trichoderma harzianum and their bean rhizosphere competence. Mycol Res. 1997;101:1389-92.

37. Jiang YT, Zeng XH, Luque R, Tang X, Sun Y, Lei TZ, et al. Cooking with active oxygen and solid alkali: a promising alternative approach for lignocellulosic biorefineries. Chemsuschem. 2017;10(20):3982-93.

38. Kasbekara M, Fischer G, Mott BT, Yasgar A, Hyvonen M, Boshoff HIM, et al. Selective small molecule inhibitor of the Mycobacterium tuberculosis fumarate hydratase reveals an allosteric regulatory site. P Natl Acad Sci USA. 2016;113(27):7503-8.

39. Reyes-Sosa FM, Morales ML, Gomez AIP, Crespo NV, Zamorano LS, RochaMartin J, et al. Management of enzyme diversity in high-performance cellulolytic cocktails. Biotechnol Biofuels. 2017;10:156.

40. Sperandio GB, Ferreira EX. An overview of Trichoderma reesei co-cultures for the production of lignocellulolytic enzymes. Appl Microbiol Biot. 2021;105(8):3015-25. 
41. Mandels M, Weber J. The Production of cellulases. In: Hajny GJ, Reese ET, editors. Cellulases and their applications. Advances in chemistry, vol. 95 Washington: American Chemical Society; 1969. p. 391-414.

42. Mandels MH, Andreotti RE, Roche CJB, Symposium B. Measurement of saccharifying cellulase. Biotechnol Bioeng Symp. 1976;16(6):21-33.

43. Ghose TK. Measurement of cellulase activities. Pure Appl Chem. 1987:59(2):257-68.

44. Berghem LER, Pettersson LG. The Mechanism of Enzymatic Cellulose Degradation. Eur J Biochem. 1974;46(2):295-305. https://doi.org/10.1111/j. 1432-1033.1974.tb03621.x

45. Dashtban M, Maki M, Leung KT, Mao CQ, Qin WS. Cellulase activities in biomass conversion: measurement methods and comparison. Crit Rev Biotechnol. 2010;30(4):302-9.
46. Ding N, Song X, Jiang Y, Luo B, Zeng X, Sun Y, et al. Cooking with active oxygen and solid alkali facilitates lignin degradation in bamboo pretreatment. Sustainable Energy Fuels. 2018;2(10):2206-14.

47. Xue Y, Han J, Li YY, Liu J, Gan LH, Long MN. Promoting cellulase and hemicellulase production from Trichoderma orientalis EU7-22 by overexpression of transcription factors Xyr1 and Ace3. Bioresource Technol. 2020;296:122355

\section{Publisher's Note}

Springer Nature remains neutral with regard to jurisdictional claims in published maps and institutional affiliations.
Ready to submit your research? Choose BMC and benefit from:

- fast, convenient online submission

- thorough peer review by experienced researchers in your field

- rapid publication on acceptance

- support for research data, including large and complex data types

- gold Open Access which fosters wider collaboration and increased citations

- maximum visibility for your research: over 100M website views per year

At BMC, research is always in progress.

Learn more biomedcentral.com/submissions 